\title{
CCGT and small nuclear SMR hybrids system for flexible energy generation
}

\author{
Ludwik Pieńkowski ${ }^{1,{ }^{*}}$, Marek Jaszczur ${ }^{1}$, Michat Dudek ${ }^{1}$, and Katarzyna Skolik ${ }^{1}$ \\ ${ }^{1}$ AGH - University of Science and Technology, Faculty of Energy and Fuels, Kraków 30-059, \\ Al. Mickiewicza 30, Poland
}

\begin{abstract}
Future development of the energy conversion systems will be based on second and third generation technology. Additionally, modern power plants are expected to be able to work in a very wide range of power output. At the same time, frequent and rapid changes in generated power reduce systems lifetime, their average efficiency, and in the case of nuclear energy, introduce additional issues related to nuclear safety. The hybrid energy systems can give at least a partial solution to such challenges. In the present work, a thermodynamic analysis of a hybrid system consisting of a nuclear block powered by Small Modular Reactor (SMR) and a gas-steam block Gas Turbine Combined Cycle (GTCC) was performed. The coupling was made by means of a compressor in a gas block powered by an electric motor and using steam from a nuclear block in the Gas Turbine Combined Cycle steam power plant block. Some promising and challenging results are shown and discussed.
\end{abstract}

\section{Introduction}

Energy consumption is the primary indicator showing the development of the country. The growing demand for electrical energy and rapid development of power technology as well as materials science allow to design and implement modern solutions for nuclear energy, energy security and energy conversion system in order to provide a lower cost of energy. Future development of the energy conversion systems will be based on second and third generation technology as well as modern power plants are expected to be able to work in a very wide range of power output, going down to $20 \%$. In parallel to that frequent, deep and rapid changes in generated power reduce systems lifetime, their average efficiency, and in the case of nuclear energy, introduce additional issues related to nuclear safety. The hybrid energy systems can give at least a partial solution to such challenges. However, it requires significant investments which reduces their attractiveness. Such a hybrid system may constitute a very appealing solution to be implemented mainly for the future use of natural gas or synthetic gas ensuring the lowest level of the $\mathrm{CO}_{2}$ emission.

In the energy sector, there is a tendency to deploy units of larger and larger power. This trend, named scale effect, is common for all power technologies, including nuclear, coal, gas technologies and also windmills. Scale effect had stimulated the growth of the nuclear sector

\footnotetext{
* Corresponding author: pienkows@agh.edu.pl
} 
in the past. However, nowadays it seems that the huge investment cost for a single nuclear power unit is one of the main obstacles for new constructions. Unfortunately, any idea to scale down existing reactors design is not the best solution either. The comparison between the costs of a single, large power plant of $1340 \mathrm{MW}$, with an equivalent cluster of four smaller units, each with a capacity of $335 \mathrm{MW}$, has been shown by Carelli et at. [1]. According to their analysis, small reactors are capable to reach competitiveness but only after massive implementation, making profits from standardization, construction modularity, and first of all from the technological innovations.

Competitiveness is a key factor in the SMRs (Small Modular Reactors) development and the scale effect is strongly against SMRs. This effect can be measured by the coefficient, $n$, defined as the ratio of the relative increase of the $\operatorname{cost} C$ and the relative increase of the power $\mathrm{P}$ as follows:

$$
n=\frac{\Delta C / C}{\Delta P / P}
$$

Roughly, for the spherical shape the reactor power, $P$ is proportional to the reactor vessel volume, depends on the reactor size (its radius or hight) to the third power $R^{3}$. The reactor $\operatorname{cost} C$ is proportional to the amount of used construction materials and therefore to the reactor vessel surface. It depends on the reactor size squared $R^{2}$. Within this simplified assumption the solution of eq. (1) is $n=0.67$ and scale effect equation can be written as:

$$
\frac{d C}{d P}=0.67 \cdot \frac{C}{P}
$$

The value $n=0.67$ fits to the results of a much more detailed analysis presented in [1] that shows $n=0.62$. Within this simple model, it is also possible to compare the cost of a cluster of $k$ SMRs and the cost of the equivalent large reactor. Factor $c$ shows the ratio between these two costs:

$$
c=k^{1-n}
$$

Using eq. (3) for $k=4$ one can get the result $c=1.6$ which means that the cost of a cluster of four small reactors is 1.6 times higher than the cost of the large reactor of the same power. Estimated value $c=1.6$ is close to $c=1.7$ presented in [1].

Concluding, even an extremely simplified model gives a reasonably good estimation of the role of the scale effect. However, what is more interesting, such a model shows also that SMRs are potentially safer than the large reactors. The reactor safety greatly depends on the efficiency and reliability of the emergency systems that remove decay heat power, i.e. the heat power generated only by the radioactive isotopes decay when the fission chain reaction is already stopped. Similarly, as before the reactor decay heat power, $\mathrm{P}$, is proportional to the reactor vessel volume and the amount of the decay heat power that can be passively evacuated through the reactor vessel surface, $\mathrm{S}$, is proportional to this surface. Thus, the ratio $P / S$ depends on power $P$ according to the formula: $P / S \sim P^{0.33}$. Comparing two reactor systems: single large reactor $1340 \mathrm{MW}$ and the cluster of four reactors, each $335 \mathrm{MW}(4 * 335=1340$, as in [1]) one realizes that SMR cluster can passively evacuate through the reactors vessel surface $\sim 1.58$ more decay heat than a single, large power reactor. This estimation gives an overall view of the scale effect, and for further analysis, the more realistic models, such as in ref. [1] should be used. In conclusion, it can be claimed that small reactors are safer than large reactors, their safety systems are simple, reliable and relatively cheap what shows the path to achieve competitiveness by SMRs. Indeed, the licensing procedures in the US-NRC already confirmed that NuScale's light water reactor can operate safely without any safetyrelated electrical systems [2], and the emergency zones could be much smaller than $16 \mathrm{~km}$ what is currently the standard in the US [3]. 
A higher safety level opens up new opportunities for nuclear energy, including the possibility to construct SMRs in the vicinity of other industrial installations. In many analysis cogeneration systems are examined, where the heat and electricity generated by the nuclear reactor supply technological processes, in particular hydrogen production and storage [4-7]. Another widely studied process is a desalination of seawater [8]. The possibility of using a nuclear reactor as a heat source to drive the methane reforming reaction and other processes, including low-temperature processes in refineries were also investigated $[9,10]$.

The current publication shows the analysis of a hybrid energy system that connects SMR and a gas-steam power plant. In general, all hybrid systems have significant potential to match the generated power to the current energy demand from. The analysis of several coupling methods was performed that maximizes the flexibility of the generated electrical power but keeps almost constant thermodynamic parameters of the key elements of the system. The second constraint is crucial for systems lifetime, thermodynamic efficiency and nuclear reactor safety.

\section{Cycle Design}

The design of the innovative gas turbine combined cycle coupled with a small light water modular, nuclear reactor SMR is shown on Figs. 1-2 in two configurations. The system presented in Figure 1 is equipped with a classic set of devices that are part of the typical gas turbine combined cycle. It consists of a single-pressure HRSG waste heat recovery system that is obeyed by a set of machines and devices that are part of the steam cycle. In addition to that, the system was equipped with a second set of devices including the single-pressure waste heat recovery system powered by steam generated in the nuclear part of the system. The system presented in Figure 1 proposes a direct use of devices including the classical gas turbine with a direct connection to the air compressor with a gas expander on one shaft. In the system presented in Fig. 2, a modification has been made in the direct connection of the compressor. The compressor presented in the system is driven by the electric motor which is supplied from an electric generator of a modular nuclear reactor and an electric gas turbine generator to cover the motor electrical demand in various operating conditions of the gas turbine combined cycle. The variability of operating conditions of the gas turbine combined cycle depending on the demand of the energy system was changed by regulating the mass flow of the combusted gas in the range $1-10 \mathrm{~kg} / \mathrm{s}$.

Table 1. Assumption for thermodynamic analysis of the cycle - nuclear part

\begin{tabular}{|l|c|c|}
\hline \multicolumn{1}{|c|}{ Parameters } & Symbol & Value \\
\hline Nuclear reactor thermal power & $\mathrm{Q}$ & $191 \mathrm{MW}_{\text {th }}$ \\
\hline Reactor outlet temperature, steam secondary loop & $\mathrm{T}_{\text {ROUT }}$ & $300^{\circ} \mathrm{C}$ \\
\hline Reactor coolant pressure, secondary loop & $\mathrm{p}_{\mathrm{R}}$ & $35 \mathrm{bar}$ \\
\hline Coolant flow rate in secondary loop & $\dot{m}$ & $67 \mathrm{~kg} / \mathrm{s}$ \\
\hline Working fluid in the gas cycle & - & air/flue gas $/$ steam \\
\hline Gas turbine inlet pressure & $\mathrm{p}_{\text {inGT }}$ & $15.8 / 7.75 / 3.163$ bar \\
\hline Gas Turbine Inlet Temperature & $\mathrm{G}_{\mathrm{TIT}}$ & $1400 / 1315 / 1236^{\circ} \mathrm{C}$ \\
\hline Gas expander isentropic efficiency & $\eta_{\text {is }}$ & 82.5 \\
\hline Steam temperature before Steam Turbine & $\mathrm{S}_{\mathrm{TIT}}$ & $565{ }^{\circ} \mathrm{C}$ \\
\hline Steam temperature after the steam turbine & & $28.96{ }^{\circ} \mathrm{C}$ \\
\hline Steam turbine isentropic efficiency & $\eta_{\text {is }}$ & $87.8 \%$ \\
\hline Gas/steam turbine electrical efficiency & $\eta_{e}$ & 0.9856 \\
\hline
\end{tabular}




\section{Assumptions for thermodynamic calculations}

The main assumptions for the thermodynamic cycle from Fig. 1-2 are shown in Table 1.

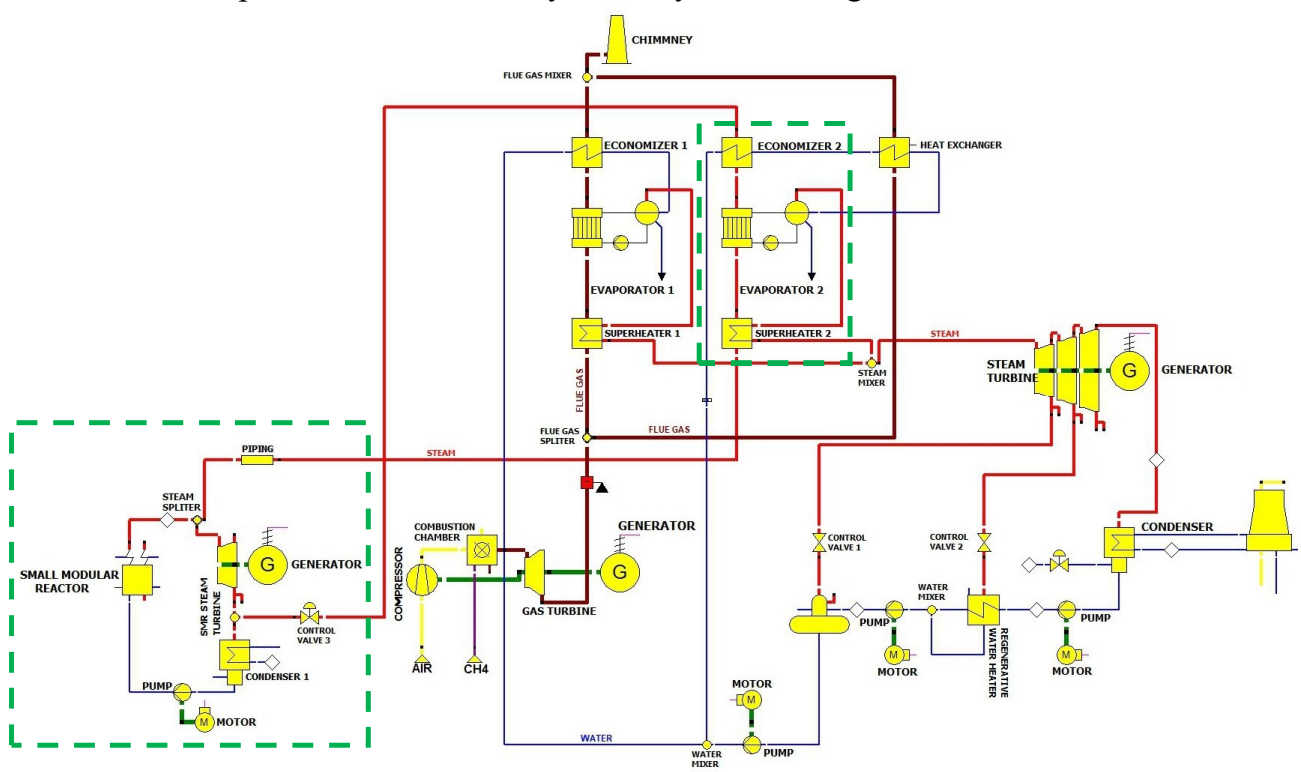

Fig. 1. Gas Turbine Combined Cycle coupled with the small nuclear reactor with shaft connection between the gas turbine and main compressor

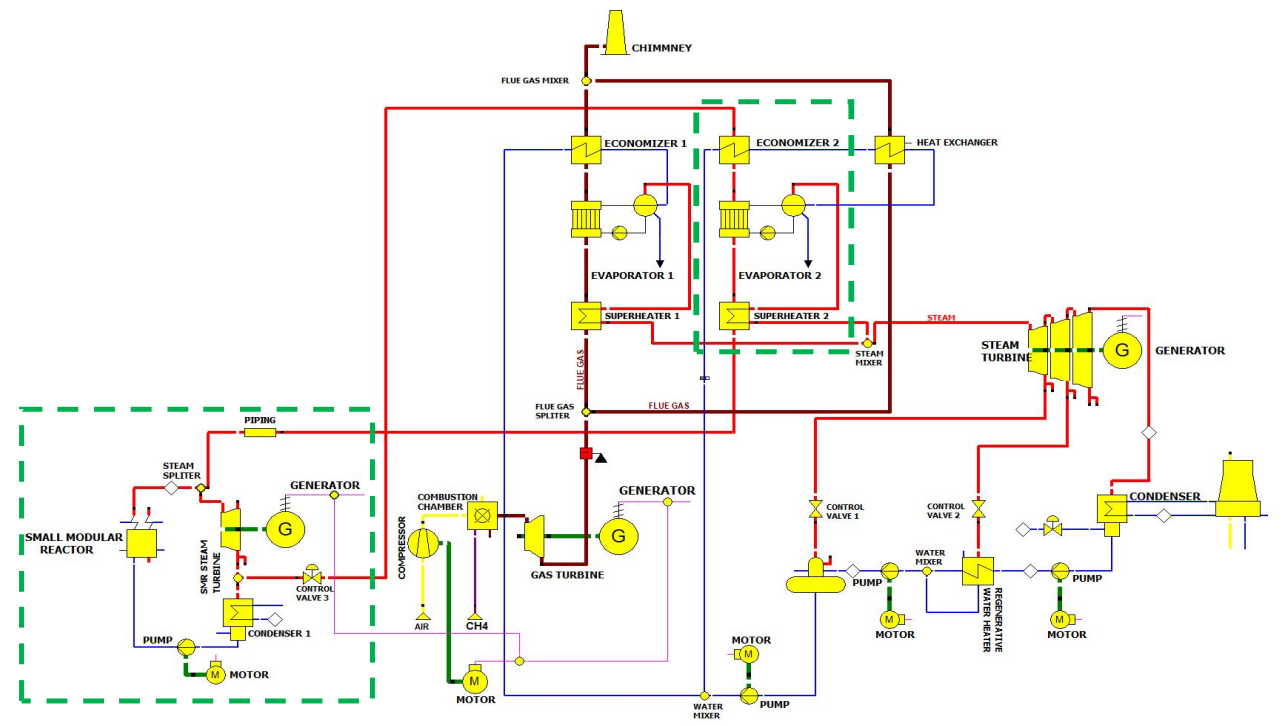

Fig. 2. Gas Turbine Combined Cycle coupled with the small nuclear reactor without shaft connection between the gas turbine and main compressor 


\section{Mathematical Model}

The calculations were made using Ebsilon Professional software which was provided by Steag Energy Services. Mathematical models for the key components of the cycle are presented in Tables 2-7.

Table 2. Thermodynamic model of the compressor

\begin{tabular}{|c|l|c|}
\hline $\mathrm{m}_{2}=\mathrm{m}_{1}$ & $\mathrm{~s}_{1}=\mathrm{f}\left(\mathrm{p}_{1}, \mathrm{~T}_{1}\right)$ & $\mathrm{T}_{2 \mathrm{~s}}=\mathrm{f}\left(\mathrm{p}_{2}, \mathrm{~s}_{1}\right)$ \\
\hline $\mathrm{h}_{2} \mathrm{~s}=\mathrm{f}\left(\mathrm{p}_{2}, \mathrm{~T}_{2 \mathrm{~S}}\right)$ & $\mathrm{dh}_{\mathrm{s}}=\mathrm{h}_{2 \mathrm{~s}}-\mathrm{h}_{1}$ & $\mathrm{dh}=\mathrm{d}_{\mathrm{hS}} / \mathrm{ETA}_{\mathrm{I}}$ \\
\hline $\mathrm{h}_{2}=\mathrm{h}_{1}+\mathrm{dh}$ & $\mathrm{T}_{2}=\mathrm{f}_{2}\left(\mathrm{p}_{2}, \mathrm{~h}_{2}\right)$ & $\mathrm{Q}_{2}=\mathrm{m}_{2} \mathrm{~h}_{2}$ \\
\hline $\mathrm{h}_{3}=\left(\mathrm{m}_{2} \mathrm{~h}_{2}-\mathrm{m}_{1} \mathrm{~h}_{1}\right) /\left(\mathrm{m}_{3} \mathrm{ETA}_{\mathrm{M}}\right)$ & $\mathrm{V}_{\mathrm{l}}=\mathrm{f}\left(\mathrm{p}_{1}, \mathrm{~T}_{1}\right)$ & $\mathrm{V}_{\mathrm{m} \mathrm{l}}=\mathrm{m}_{1} \mathrm{v}_{1}$ \\
\hline
\end{tabular}

Table 3. Thermodynamic model of the gas turbine

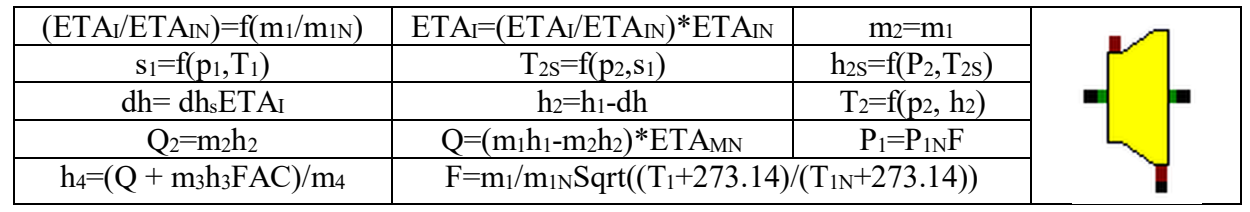

Table 4. Thermodynamic model of the steam turbine

\begin{tabular}{|c|c|c|c|}
\hline $\mathrm{x}_{1}=\mathrm{f}\left(\mathrm{p}_{1}, \mathrm{~h}_{1}\right)$ & $\mathrm{s}_{1}=\mathrm{f}\left(\mathrm{p}_{1}, \mathrm{~h}_{1}\right)$ & $\mathrm{V}_{1}=\mathrm{f}\left(\mathrm{p}_{1}, \mathrm{~h}_{1}\right)$ & \\
\hline $\mathrm{V}_{\mathrm{m} 1}=\mathrm{m}_{1} \mathrm{~V}_{1}$ & $\mathrm{~S}_{2 \mathrm{~S}}=\mathrm{S}_{1}$ & $\mathrm{~h}_{2 \mathrm{~S}}=\mathrm{f}\left(\mathrm{p}_{2}, \mathrm{~s}_{22}\right)$ & \\
\hline $\mathrm{dh}_{\mathrm{s}}=\mathrm{h}_{1}-\mathrm{h}_{2 \mathrm{~S}}$ & $\mathrm{~F}_{\mathrm{AK}}=\mathrm{m}_{1} / \mathrm{m}_{1 \mathrm{~N}}$ & $\mathrm{ETA}_{\mathrm{I}}=\mathrm{ETA}_{\mathrm{IN}} * \mathrm{f}\left(\mathrm{F}_{\mathrm{AK}}\right)$ & \\
\hline $\mathrm{F}_{\mathrm{AK}}=\left(\mathrm{p}_{1} / \mathrm{p}_{2}\right) /\left(\mathrm{p}_{1 \mathrm{~N}} / \mathrm{p}_{2 \mathrm{~N}}\right)$ & $\mathrm{ETA}_{\mathrm{I}}=\mathrm{ETA}_{\mathrm{IN}} * \mathrm{f}\left(\mathrm{F}_{\mathrm{AK}}\right)$ & $\mathrm{F}_{\mathrm{AK}}=\mathrm{V}_{\mathrm{ml}} / \mathrm{V}_{\mathrm{m} 1 \mathrm{~N}}$ & \\
\hline $\mathrm{ETA}_{\mathrm{I}}=\mathrm{ETAA}_{\mathrm{IN}} * \mathrm{f}\left(\mathrm{F}_{\mathrm{AK}}\right)$ & $\mathrm{dh}_{2 \mathrm{~L}}=\mathrm{d}_{\mathrm{h} 2 \mathrm{LN}}$ & $\mathrm{F}_{\mathrm{AK}}=\mathrm{V}_{\mathrm{m} 2} / \mathrm{V}_{\mathrm{m} 2 \mathrm{~N}}$ & \\
\hline $\mathrm{x}_{2}=\mathrm{f}\left(\mathrm{p}_{2}, \mathrm{~h}_{2}\right)$ & $\mathrm{T}_{2}=\mathrm{f}\left(\mathrm{p}_{2}, \mathrm{~h}_{2}\right)$ & $\mathrm{m}_{1}=\mathrm{m}_{2}+\mathrm{m}_{3}+\mathrm{m}_{4}$ & \\
\hline
\end{tabular}

Table 5. Thermodynamic model of the evaporator

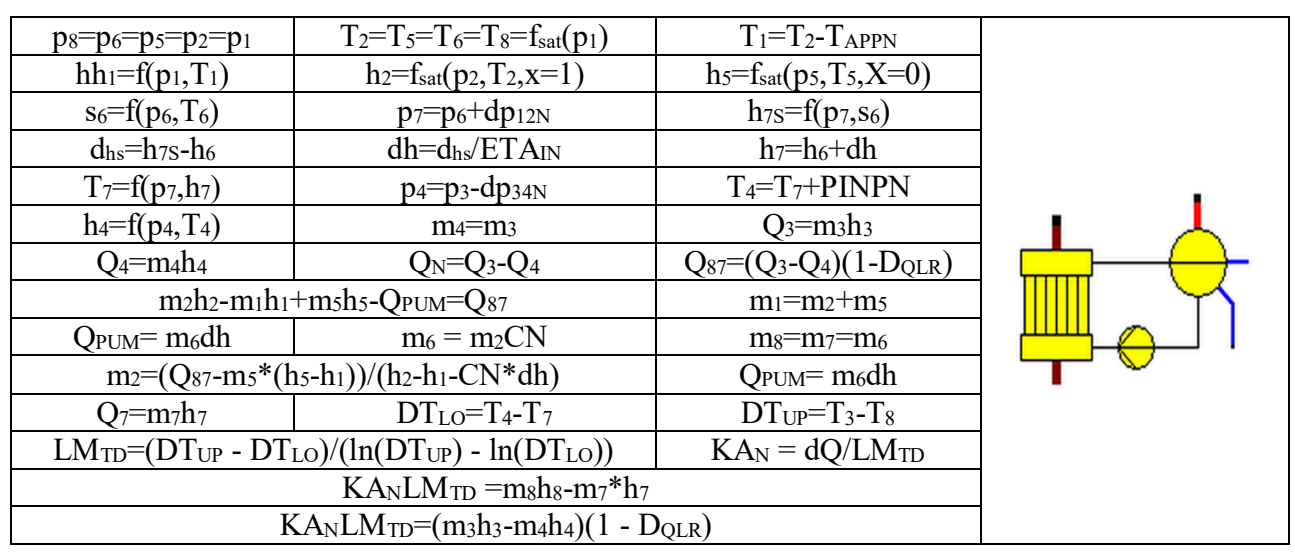

Table 6. Thermodynamic model of the pump

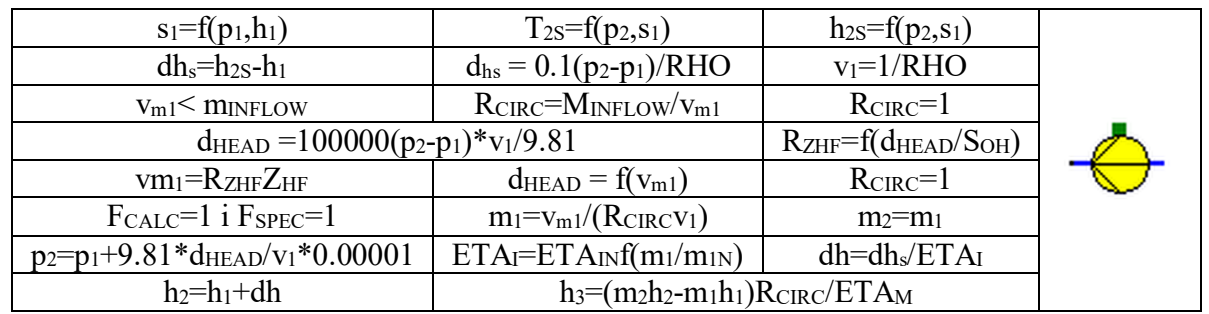


Table 7. Thermodynamic model of the condenser

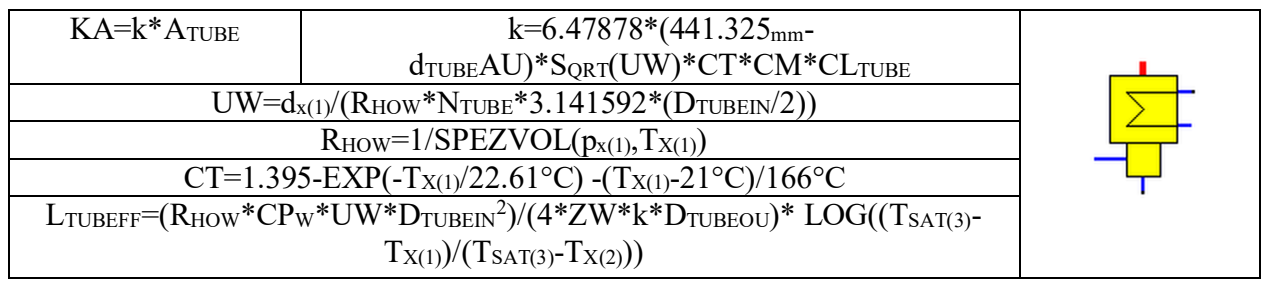

\section{Results and discussion}

Results of thermodynamic calculation for the Gas Turbine Combined Cycle (GTCC) coupled with Small Modular Nuclear Reactor are shown in the Figs. 3 and 4.

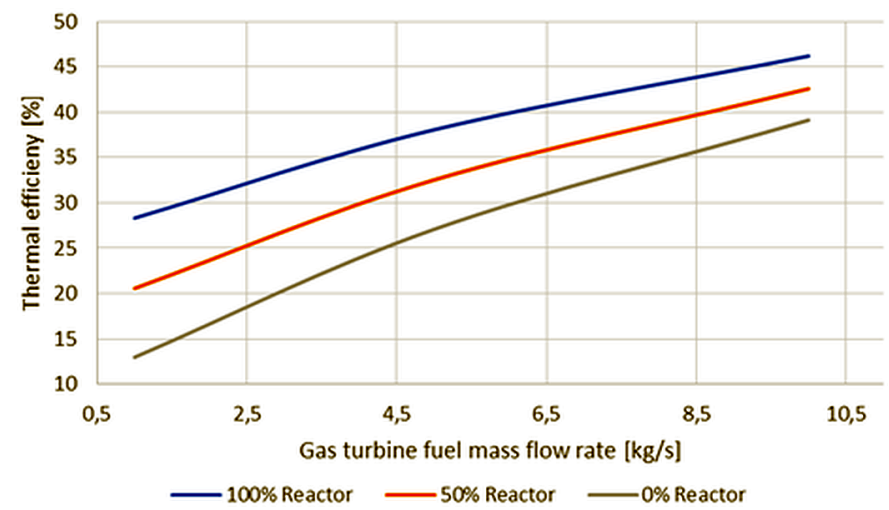

Fig. 3a. Thermal efficiency vs Gas turbine fuel mass flow rate

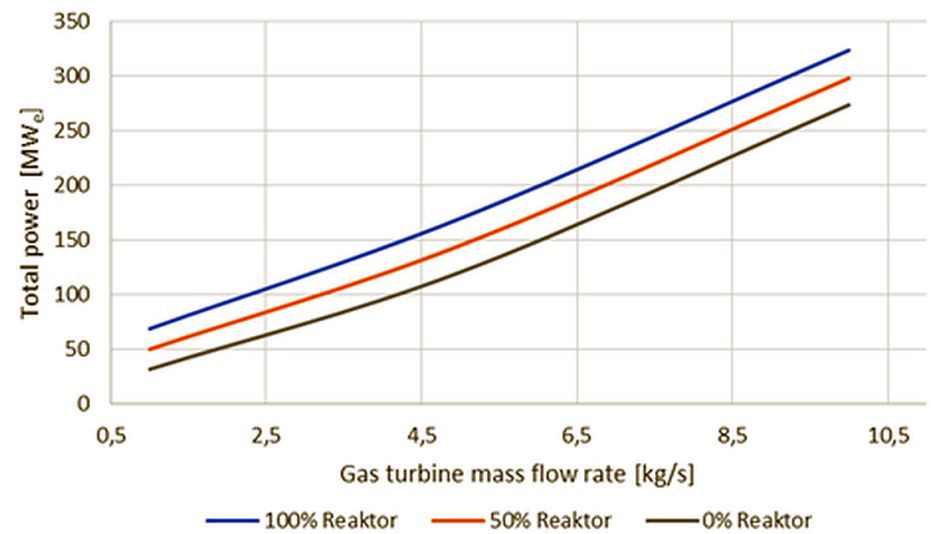

Fig. 3b. Total power vs Gas turbine fuel mass flow rate

The nuclear power plant operates independently of the gas-steam power plant in the case of high power demand. The system is able to operate in a load following mode changing only the gas turbine fuel mass flow rate. The results of the analysis presented by the blue lines and labelled "100\% Reactor" show that there is no steam transfer from the nuclear part to CCGT. 
If there is a lower power demand, the gas fuel flow rate is reduced, however, the steam turbine in the CCGT system is supported by the steam generated in the nuclear part transferring $50 \%$ of the steam to the CCGT system. In Figures 3 and 4, the results for such case are shown by the red line and labelled "50\% Reactor".

The emergency scenario was also considered when there is a need to send the entire steam generated in the nuclear system to the CCGT part. The results are represented by the grey line, and they are labelled " $0 \%$ Reactor".

Figure 4 shows the results when the main compressor of a gas turbine is powered by an electric motor. In this case, the systems are coupled both by the steam transfer and electrically where the air compressor is powered by the motor connected through two electric generators.

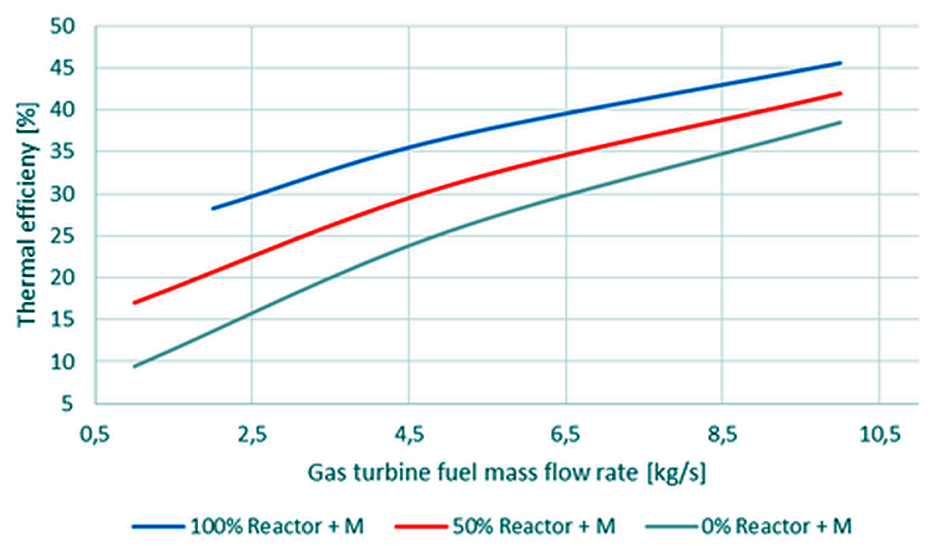

Fig. 4a. Steam coupling and main CCGT compressor driven by an electrical motor. Thermal efficiency vs Gas turbine fuel mass flow rate

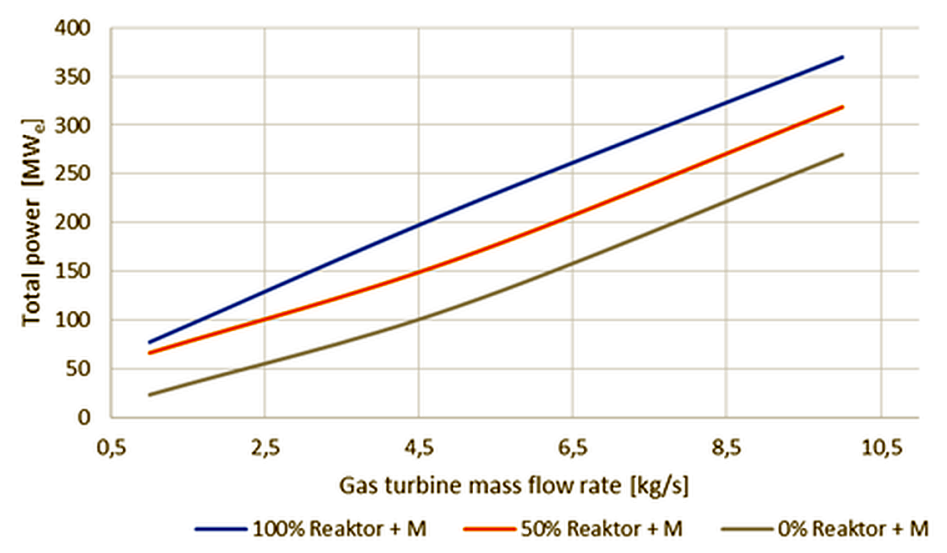

Fig. 4b. Steam coupling and main CCGT compressor driven by an electrical motor. Total power vs Gas turbine fuel mass flow rate

In all considered scenarios, the thermal power of a nuclear reactor is constant, equal to $191 \mathrm{MW}_{\text {th }}$ and the steam generated flow rate is also constant and equal to $67 \mathrm{~kg} / \mathrm{s}$. It was also ensured that in all analysed scenarios the steam turbine in the CCGT system operates so that this part has at least a minimal steam supply. 


\section{Conclusions}

In the present paper, the operation of the gas turbine combined cycle (GTCC) coupled thermally with the small modular nuclear reactor (SMR) is analysed for two configurations. In the first one, the compressor is directly connected to the gas expander while in the second one the compressor is powered by an electric motor.

Both configurations enable the operation of a steam turbine in the GTCC part when the power demand is low. Thanks to this solution, the power generated by the system can follow the power demand in a very wide range. A drop in the system efficiency depends on the thermal load of SMR and GTCC, changes significantly for the low heat load.

The efficiency of energy conversion in the proposed system varies from $9 \%$ to $30 \%$ for the lowest thermal load conditions and configuration presented in this paper. Depends on the load level of the gas turbine combined cycle system working directly with small modular nuclear reactor in SMR with $100 \%$ thermal load of the gas turbine combined cycle allows to produce electricity with efficiency in the range of $37-46 \%$.

Acknowledgement. The present work was supported by AGH University Grant No.11.11.210.312 and No. 11.11.210.377 and PROCHEM S.A. engineering company.

\section{References}

1. M.D. Carelli, P. Garrone, G. Locatelli, M. Mancini, C. Mycoff, P. Trucco, M.E. Ricotti, Progress in Nuclear Energy 52, 4, 403 (2010)

2. NRC agrees NuScale SMR needs no back-up power. Available on 6-SEP-2018 http://www.world-nuclear-news.org/RS-NRC-agrees-NuScale-SMR-needs-no-backup-power-1001184.html

3. US regulators discuss smaller SMR emergency zones. Available on 6-SEP-2018 http://www.world-nuclear-news.org/Articles/US-regulators-agree-smaller-SMRemergency-zones

4. G. Locatelli, S. Boarin, A. Fiordaliso, E. Ricotti, Energy 148, 494, (2018)

5. G. Locatelli, A. Fiordaliso, S. Boarin, M.E. Ricotti Progress in Nuclear Energy 97, 153, (2017)

6. M. Dudek, Z. Kolenda, M. Jaszczur, W. Stanek, J. Energy Resour. Technol 140 (2), 020910 (2018)

7. M. Dudek, M. Jaszczur, E3S Web of Conferences 14, 01046 (2017)

8. D.T. Ingersoll, Z.J. Houghton, R. Bromm, C. Desportes, Desalination 340, 84 (2014)

9. M.A. Futterer, J. Carlsson, S. de Groot, M. Deffrennes, A. Bredimas. Nuclear Engineering and Design 271, 73, (2014)

10. M. Dudek, M. Jaszczur, K. Skolik, M. Malicki, L. Pieńkowski, E3S Web of Conferences 10, 00105 (2016) 